7-1-2015

\title{
Perceptions of Physician Assistant Students' Readiness with System-Based vs. Problem-Based Physical Diagnosis Curriculum
}

\author{
Kelly Donkers \\ Chatham University, kdonkers@chatham.edu \\ Carl Garrubba \\ Chatham University \\ Laura Daniel \\ Independent Contractor \\ Carol Ennulat \\ UPMC Cancer Center
}

Follow this and additional works at: https://nsuworks.nova.edu/ijahsp

Part of the Medicine and Health Sciences Commons

\section{Recommended Citation}

Donkers K, Garrubba C, Daniel L, Ennulat C. Perceptions of Physician Assistant Students' Readiness with System-Based vs. Problem-Based Physical Diagnosis Curriculum. The Internet Journal of Allied Health Sciences and Practice. 2015 Jul 01;13(3), Article 9.

This Manuscript is brought to you for free and open access by the College of Health Care Sciences at NSUWorks. It has been accepted for inclusion in Internet Journal of Allied Health Sciences and Practice by an authorized editor of NSUWorks. For more information, please contact nsuworks@nova.edu. 


\title{
Perceptions of Physician Assistant Students' Readiness with System-Based vs. Problem-Based Physical Diagnosis Curriculum
}

\begin{abstract}
Purpose: The purpose of this study was to identify students' perceptions of the curriculum in two different cohorts who received two different delivery styles (system-based or problem-based) of physical diagnosis curriculum to determine if significant differences were present, and to identify how each cohort performed on their clinical experiences (CEs). Methods: One-hundred and sixteen students at one physician assistant (PA) program from two cohorts of students were surveyed using a true/false survey (analyzed by chisquare) regarding their perceptions of their preparedness for clinical rotations with regard to the ability to perform physical examinations. Clinical preceptor evaluations were also analyzed for both cohorts with respect to competence in physical examination skills as rated by preceptors on a scale of 1 to 3 . Results: Each cohort related that they were satisfied with their preparation regardless of delivery format, with no tendencies toward respective cohorts indicating they should have received the alternate delivery format. No significant differences were found in the students' perceptions of their ability to perform a physical examination on CEs between the cohorts or between the groups' performances on their CEs. Conclusions: System-based and problem-based formats were found to have merit and similar outcomes and thus can both be deemed effective teaching methods for teaching physical diagnosis curriculum.
\end{abstract}




\title{
IJAHSPP \\ The Internet Journal of Allied Health Sciences and Practice \\ Dedicated to allied health professional practice and education \\ http://ijahsp.nova.edu Vol. 13 No. 3 ISSN 1540-580X
}

\section{Perceptions of Physician Assistant Students' Readiness with System-Based vs. Problem-Based Physical Diagnosis Curriculum}

\author{
Kelly Donkers, MPA, PA-C1 \\ Carl Garrubba, MPA, PA-C2 \\ Laura Daniel, $\mathrm{PhD}^{3}$ \\ Carol Ennulat, MBA, PA-C4
}

1. Chatham University, Physician Assistant Studies Department, Pittsburgh, PA

2. Chatham University, Physician Assistant Studies Department, Pittsburgh, PA

3. Independent Contractor, Pittsburgh, PA

4. Director, Advance Practice Provider Relations, UPMC Cancer Center, Hillman

Cancer Center, Pittsburgh, PA

United States

CITATION: Donkers K, Garrubba C, Daniel L, Ennulat C. Perceptions of Physician Assistant Students' Readiness with SystemBased vs. Problem-Based Physical Diagnosis Curriculum. The Internet Journal of Allied Health Sciences and Practice. July 2015. Volume 13 Number 3.

\begin{abstract}
Purpose: The purpose of this study was to identify students' perceptions of the curriculum in two different cohorts who received two different delivery styles (system-based or problem-based) of physical diagnosis curriculum to determine if significant differences were present, and to identify how each cohort performed on their clinical experiences (CEs). Methods: One-hundred and sixteen students at one physician assistant (PA) program from two cohorts of students were surveyed using a true/false survey (analyzed by chi-square) regarding their perceptions of their preparedness for clinical rotations with regard to the ability to perform physical examinations. Clinical preceptor evaluations were also analyzed for both cohorts with respect to competence in physical examination skills as rated by preceptors on a scale of 1 to 3 . Results: Each cohort related that they were satisfied with their preparation regardless of delivery format, with no tendencies toward respective cohorts indicating they should have received the alternate delivery format. No significant differences were found in the students' perceptions of their ability to perform a physical examination on CEs between the cohorts or between the groups' performances on their CEs. Conclusions: Systembased and problem-based formats were found to have merit and similar outcomes and thus can both be deemed effective teaching methods for teaching physical diagnosis curriculum.
\end{abstract}

\section{INTRODUCTION}

The two models of medical education that are the more widely used are lecture-based learning (LBL) and problem-based learning (PBL). ${ }^{1}$ There are various delivery methods for PBL, but all use patient problems as the focus of instruction. Programs can use both text and multimedia formatted clinical case scenarios to deliver PBL. ${ }^{2}$ LBL is signified by traditional format of lecture and laboratory skills. ${ }^{1,2}$

The PA program participating in this study has utilized PBL as the focus of its curriculum since its inception in 1995. Students are presented with approximately 42 PBL patients over the course of two semesters. The utilization of this technique is the core of the curriculum around which other courses are structured. "PBL is a student-centered model that stimulates clinical reasoning, promotes the application and retention of knowledge, and encourages self-directed, lifelong learning" as applied to a clinical problem.3,4 Potential advantages of a PBL-based curriculum over a traditional LBL curriculum include clinical reasoning,

(c) The Internet Journal of Allied Health Sciences and Practice, 2015 
integration of knowledge, lifelong learning, team skills, self-reflection, self-appraisal, enjoyment, and motivation. 3,4 Students are given a clinical scenario that requires the acquisition of medical information, clinical reasoning and application, problem-solving skills, and identification of gaps in knowledge in order to advance through the clinical scenario. Students also learn to critically evaluate themselves and their peers with regard to group interaction. There can also be several perceived disadvantages of $\mathrm{PBL}$, including the differences in self-directed behaviors of students and variability in knowledge base and participation in the process. Anecdotally, variability can be seen in the learning curve to this format for many students who have not experienced non lecture-based learning that may be problematic for some students.

The process of acquiring the skill of clinical reasoning can be difficult, and many factors affect a student's ability to master it. ${ }^{5}$ Clinical reasoning does remain the cornerstone of medical curricula, and an optimal method to teach this skill has not been identified because the process is multi-factorial. 4-10 $^{-10}$ Many methods other than LBL, system-based learning (SBL, where student's learn skills per organ system), and PBL have been employed by medical and osteopathic training programs in medical education.., 11 LBL can encourage a student to simply absorb facts while active-learning techniques can foster both life-long learning and a deeper understanding of material. ${ }^{11}$ With the ever-changing landscape of medicine and the increasing body of knowledge required to provide care throughout medicine and the medical sciences, the need for providers to acquire selfdirected learning techniques is desirable. ${ }^{11-14}$

Student-centered learning approaches, like PBL and case-based learning are prevalent world-wide.15-16 Frambach et al discusses the challenge of using self-directed learning in a multi-cultural environment. 15 This educational approach is a very "Western" type of pedagogy and may not be a suitable or viable option for other cultures. This study found that this type of educational approach posed a challenge to Middle-Eastern and Asian students, and that culturally sensitive approaches such as culturally specific complementary approaches would be beneficial when considering PBL education in a multi-cultural environment. Anecdotally, the authors have found that cultural differences have led to challenging issues in the PBL setting, but student learning outcomes were met regardless.

PBL and CBL are used in disciplines other than medicine and allied health science education to enhance learning in a complex world. For example, in Leon et al, PBL was used to prepare Master of Public Health students to better understand and address the complexities of global health concerns. ${ }^{17}$ In this study, global health competencies were created for the curriculum and the pedagogical approach using problem/case-based learning was employed to foster a self-directed environment for learning as well as creating an environment of collaboration. Similar to the PBL approach in our institution, this one used small group learning with extensive peer to peer collaboration with peer evaluation and attainment of course competencies. It was found that this type of learning was dynamic in its approach to learning and fostered problem-solving skills among the participants ${ }^{17}$

A study of pharmacy students that compared didactic lecture format and team-based learning (self-directed learning in small groups, similar to PBL and CBL as described in the article) assessed students following their respective learning formats on three topics: time spent learning each topic, course examinations, and a course examination five months later. ${ }^{18}$ The study demonstrated that there was an increase in time spent learning material with the team-based learning students compared to the LBL instructed students. There was not a significant difference in course examination means either directly following the course or five months after the course. This study demonstrated equivalency for both methods. ${ }^{18}$

Over the last $60+$ years, there has been a great deal of change in the way assessment is conducted in medical education, and there are benefits and challenges with the different types of assessments. Clinical skills assessments are an essential part of physician assistant education, as multiple choice question (MCQ) examinations do not assess communication skills or patient interaction with the provider. ${ }^{19}$

Wardley et al completed a 5-year longitudinal comparison of students' acquisition of knowledge on two separate curricular tracks, PBL and LBL. ${ }^{1}$ The study highlighted evidence that the PBL model provided a solid foundation in the application of basic sciences. ${ }^{1}$ Active learning methods can be helpful to enhance student learning. ${ }^{20}$ Electronic response systems (ERS), use of case studies, peer/self-explanation, high- and low-fidelity simulation scenarios, role-playing, and problem-based learning are some currently utilized strategies for active learning. ${ }^{20}$ The physical examination and skills component of PA education can be a logical place to employ active learning techniques. In Gaur and Skochelak, it was found that inconsistencies exist between results of studies that compare objective assessment tools with regard to physical examination. ${ }^{21}$ Assessment tools should evaluate a student's clinical abilities, as well as success or failure of the curriculum delivery.

Though the clinical medicine portion of the curriculum at the authors' institution is delivered via PBL, several other courses use LBL. Examples of these courses include pharmacology, critical reading of the literature, clinical application of the basic sciences (anatomy, physiology, and clinically-related pathology), procedural/skills courses, and physical diagnosis. Until and through

(C) The Internet Journal of Allied Health Sciences and Practice, 2015 
academic year 2008-2009 (Class of 2010), the physical diagnosis (PD) course was taught via a system-based approach. In academic year 2009-2010 (Class of 2011), the PD course structure was changed to a problem-focused rather than systembased approach.

It can be difficult to assess when students are ready to make the transition toward clinical decision-making and problem-focused examinations. Many students have medical knowledge and background, while other students are making a career change into the medical field. This difference may support the teaching of system-based examinations early in didactic education, then gradually introducing problem-focused examinations. This study was performed to identify any differences in students' perceptions of their clinical readiness regarding two different delivery styles (system-based or problem-based) in their PD courses, and to identify how each cohort performed with regard to physical examination competence during their CEs (rotations).

The same two primary faculty members taught PD I and II with the support of adjunct faculty for some classroom instruction and skills assessment throughout the didactic years 2009-2010 and 2009-2010. The two primary faculty members developed the curriculum for both the problem-focused and system-based styles that were included in the study and trained the adjunct faculty members.

Students in the 2008-2009 (Class of 2010) academic year received a system-based approach of instruction. These students were taught and tested by body system alone, although the order of the systems was determined based on the cases being used in PBL sessions. Lab sessions consisted of students practicing predetermined sets of skills unattached to clinical scenarios. This option eliminated the clinical reasoning portion of the skills acquisition. They were given all the components of a physical exam (e.g. lung/respiratory examination) and were assessed on the given skills for their competencies. Clinical Reasoning was not part of the assessments that were performed in this didactic year.

For example, for the system-based cohort of students, the course began with a set of HEENT skills competencies from a prescribed list, and no clinical scenarios were used. In the problem-based cohort of students, the course began with two patients with HEENT complaints and the students were required to formulate and perform the appropriate examination specific to the patient's complaint, not the entire HEENT system as was done the previous year. This cohort was then required to use patients subsequently encountered in the PBL course to practice and demonstrate competency for physical exam skills. All HEENT topics were covered when they were encountered in the PBL course, not necessarily contemporaneously. By the end of the academic year, each cohort had learned the same set of skills, using the two different learning formats.

Students in the 2009-2010 (Class of 2011) academic year were instructed in a problem-focused fashion in the physical diagnosis course. These students would bring information from the cases used in their PBL groups to the physical examination laboratory in order to integrate the process of clinical reasoning skills with physical examination skills. For example, one of the first cases that the students encountered was an upper respiratory infection. Students gathered a chief complaint and history from the patient in PBL from a predetermined set of information contained in the PBL case. Students would use the information that they gathered in their PBL sessions to determine the pertinent physical examination required for a problem-focused approach. Students would then discuss their chosen relevant physical exam with instructors during lab sessions and practice techniques of those examinations. This process was completed for each PBL patient encountered throughout the year. Each student was evaluated three times a semester by performing a problem-focused examination using one of the PBL patient scenarios as the assessment tool. All body systems were assessed throughout the didactic year, but were always encountered through a clinical scenario. A student could therefore be assessed on several different scenarios that had been encountered in PBL. The exception was the end-of-didactic-year assessment consisting of a comprehensive physical examination including all body systems. Each of the assessments that were used for competencies was reviewed and developed by full-time and adjunct PD and PBL faculty.

The change to problem-based instruction was designed not only to focus on the skills themselves, but also to incorporate clinical reasoning skills for formulation of a proper physical exam based on a patient history.

\section{Methods}

IRB approval was obtained through this program's university. Once the clinical experience year is complete, students return to campus for a month of final instruction and summative evaluation. Anonymous surveys were distributed to each class when they returned to campus. No unique identifying information other than class graduation year was on the anonymous survey. Preceptor evaluations of physical examination competency were reviewed for each student. When the preceptor ratings were submitted for analysis, this information was de-identified.

Students were surveyed at the end of their clinical year to assess their perceptions of preparedness with regard to physical examination skills in their CEs (rotations). The cohort that received the system-based approach (class of 2010, n=59) and the

(c) The Internet Journal of Allied Health Sciences and Practice, 2015 
cohort that received the problem-focused approach (class of 2011, $n=57$ ) were surveyed using the same assessment tool. This tool was a newly created survey designed to obtain a basic understanding of student perceptions and included five true/false questions. Class year identification was also requested. Demographic items were requested, but were not included in any analysis. Two students in the class of 2010 and three students in the class of 2011 chose not to participate in the survey portion of the study. See Appendix 1 for survey tool. The surveys were tabulated for both years and the results are represented for questions 6-10 as indicated in Table 1. Each question was analyzed with a Chi-square test for statistical significance. (Insert Appendix 1 here)

Table 1. Chi-Squared Tests of Questions 6-10

\begin{tabular}{|c|c|c|c|c|}
\hline Question 6 & $\mathbf{2 0 1 0}$ & $\mathbf{2 0 1 1}$ & $\mathbf{X}_{\mathbf{1}}{ }_{1}$ & $\boldsymbol{P}$ \\
\hline True & $90.0 \%(54)$ & $91.2 \%(52)$ & 0.052 & 0.820 \\
\hline False & $10.0 \%(6)$ & $8.8 \%(5)$ & & \\
\hline Question 7 & & & & \\
\hline True & $24.6 \%(14)$ & $34.8 \%(8)$ & 0.859 & 0.354 \\
\hline False & $75.4 \%(43)$ & $65.2 \%(15)$ & & \\
\hline Question 8 & & & & \\
\hline True & $53.8 \%(14)$ & $17.9 \%(7)$ & 9.192 & 0.002 \\
\hline False & $46.2 \%(12)$ & $82.1 \%(32)$ & & \\
\hline Question 9 & & & & \\
\hline True & $30.5 \%(18)$ & $80.0 \%(20)$ & 17.362 & $<0.01$ \\
\hline False & $69.5 \%(41)$ & $20.0 \%(5)$ & & \\
\hline Question 10 & & & & \\
\hline True & $58.1 \%(18)$ & $26.1 \%(12)$ & 7.963 & 0.005 \\
\hline False & $41.9 \%(13)$ & $73.9 \%(34)$ & & \\
\hline
\end{tabular}

For the second portion of the study, each member of the class of 2010 (system-based), and the class of 2011 (problem-based) clinical experience (CE) preceptor evaluations of physical examination competency were reviewed. All students' scores in each cohort were analyzed regardless of their participation in the questionnaire, because the identity of those who did not participate was not known. During each of the nine CEs, preceptors evaluated students' competency of physical examination skills on a scale from 1 to 3 where $1=$ =inadequate, 2=adequate, and 3=exemplary. Each student's rating(s) for each clinical experience (total of $9 \mathrm{CEs}$ ) was entered into a spreadsheet. If a student had more than one preceptor, and was given multiple ratings, the average of the ratings was entered for that rotation. Each student's CE performance scores were then averaged for a total score for the year, and then an average for the cohort for the year was compared to the same data for the other class. Each student's year long average was included in a class-wide mean calculation to determine if there was a significant difference between the two class means. The order in which CEs were assigned was varied among the students for both classes. Each student completed a family practice, internal medicine, psychiatry, women's health, surgery, pediatrics, emergency medicine, and 2 elective rotations but in differing orders based on preceptor availability.

The preceptor ratings were entered for each student into a spreadsheet and were analyzed using Mann-Whitney tests. The Mann-Whitney tests were used to evaluate whether either one of the classes (class of 2010 or class of 2011) had higher preceptor evaluations than the other. If a student had received more than one evaluation from several preceptors on a rotation, they were averaged together and rounded to the appropriate whole number for that rotation. Numbers were rounded to the whole number to be consistent with the original preceptors' 1 to 3 rating scale and for purposes of the inferential Mann-Whitney tests. The alpha level of significance for all of these analyses was 0.05 .

\section{Results}

There was no significant difference between the cohorts regarding their perception of readiness to perform a problem-based physical examination. There was no significant difference between the groups regarding their preparedness based on whether the curriculum had been delivered in a problem-based or a system-based style. There was a significant relationship between the cohorts and their responses to the question, "I would have felt more prepared to complete a problem focused examination if the physical diagnosis course had been delivered in a system-based style." The class of 2010 predominantly categorized this statement as "true" as they had the course delivered in this format, while the class of 2011 predominantly categorized it as "false," indicating that they did not feel that they suffered with regard to examination preparedness having received a problemfocused delivery of the course (See Table 1). 
There was statistical significance between the groups for the question, "I would have felt more prepared IN GENERAL if the physical diagnosis course had been delivered in a case or problem-based style." The class of 2010 predominantly classified it as "false," while the class of 2011 predominantly classified it as "true." The question "I would have felt more prepared IN GENERAL if the physical diagnosis course had been delivered in a system-based style" also produced statistical significance. The class of 2010 predominantly classified it as "true" while the class of 2011 predominantly classified it as "false." The class of 2010 received system-based training, while the class of 2011 received problem-based training. The findings indicate that the majority of students did not feel that having received the alternate format would have provided additional preparedness.

The distributions of students' evaluative scores were not statistically different between the class of 2010 and the class of 2011 for any of the CEs (with regard to overall physical examination competence). All of the median and mode scores of all CEs in both years were identical, median $=$ mode $=3$. Mean scores for the class of 2010 and 2011 were 2.75 and 2.73 respectively, demonstrating no significant differences among the classes. See Tables 2 and 3.

Table 2. Mann-Whitney tests of Clinical Experiences Alpha level of significance $=0.05$

\begin{tabular}{|l|l|l|}
\hline Clinical Experience No. & \multicolumn{1}{|c|}{$\mathbf{Z}$} & \multicolumn{1}{c|}{$\boldsymbol{p}$} \\
\hline 1 & -0.138 & 0.890 \\
\hline 2 & -0.329 & 0.742 \\
\hline 3 & -1.275 & 0.202 \\
\hline 4 & -1.399 & 0.162 \\
\hline 5 & -0.322 & 0.748 \\
\hline 6 & -0.404 & 0.686 \\
\hline 7 & 0.371 & 0.711 \\
\hline 8 & -0.931 & 0.352 \\
\hline 9 & -0.417 & 0.676 \\
\hline
\end{tabular}

Table 3. Frequency Distributions of Preceptor Evaluative Ratings between the Classes of 2010 and 2011

\begin{tabular}{|l|l|l|l|l|}
\hline $\begin{array}{c}\text { Clinical } \\
\text { Experience } \\
\text { No. }\end{array}$ & $\begin{array}{c}\text { Graduation } \\
\text { Year }\end{array}$ & \multicolumn{1}{|c|}{ Inadequate } & Adequate & Exemplary \\
\hline 1 & 2010 & $1.7 \%(1)$ & $29.3 \%(17)$ & $69.0 \%(40)$ \\
\hline & 2011 & $0.0 \%(0)$ & $30.4 \%(17)$ & $69.6 \%(39)$ \\
\hline 2 & 2010 & $0 \%(0)$ & $33.3 \%(20)$ & $66.7 \%(40)$ \\
\hline & 2011 & $0 \%(0)$ & $30.5 \%(18)$ & $69.5 \%(41)$ \\
\hline 3 & 2010 & $0 \%(0)$ & $23.7 \%(14)$ & $76.3 \%(45)$ \\
\hline 4 & 2011 & $0 \%(0)$ & $34.5 \%(20)$ & $65.5 \%(38)$ \\
\hline & 2010 & $0 \%(0)$ & $20.0 \%(12)$ & $80.0 \%(48)$ \\
\hline 5 & 2011 & $0 \%(0)$ & $31.5 \%(17)$ & $68.5 \%(37)$ \\
\hline & 2010 & $0 \%(0)$ & $29.8 \%(17)$ & $70.2 \%(40)$ \\
\hline 6 & 2011 & $0 \%(0)$ & $27.1 \%(16)$ & $72.9 \%(43)$ \\
\hline & 2010 & $0 \%(0)$ & $19.0 \%(11)$ & $81.0 \%(47)$ \\
\hline 7 & 2011 & $0 \%(0)$ & $16.1 \%(9)$ & $83.9 \%(47)$ \\
\hline & 2010 & $0 \%(0)$ & $24.1 \%(14)$ & $75.9 \%(44)$ \\
\hline 8 & 2011 & $0 \%(0)$ & $21.2 \%(11)$ & $78.8 \%(41)$ \\
\hline & 2010 & $0 \%(0)$ & $25.0 \%(15)$ & $75.0 \%(45)$ \\
\hline 9 & 2011 & $0 \%(0)$ & $17.9 \%(10)$ & $82.1 \%(46)$ \\
\hline & 2010 & $0 \%(0)$ & $15.3 \%(9)$ & $84.7 \%(50)$ \\
\hline
\end{tabular}

\section{Discussion}

Based on the results, the collection of data for this study has demonstrated that both formats of instruction have merit and are perceived by the respective groups as effective. The strengths of the problem-focused format engage the student in clinical reasoning skills at the beginning of their didactic education, while system-based assessments offer solid objective educational 
goals and ensure that all students have the knowledge of all of the components of the physical examination. A review of 14 primary studies and four systematic reviews involving allied health professions identified that there is not a specific teaching approach that optimizes learning outcomes, regardless of teaching/learning environment. There is not one identified style or combination of styles that strengthens outcomes, and therefore the individual program, philosophy, and resources must be considered. ${ }^{22}$ The data supports the benefit of both formats, and as a result of these findings, the curriculum reflects components of both styles of instruction. Students beginning with the class of 2014 have received system-based instruction and assessment, as well as problem-focused assessments to judge their clinical reasoning. The faculty recognizes the importance of building a student's clinical thinking with problem-focused examination, as well as the need to cover all components of the physical examination in a system-based fashion to assess competence of the student. This study served to evaluate the students' readiness (both perceived and as judged by preceptors) to perform a physical examination during their clinical experiences.

Limitations of the study were considered after analysis. The study is limited to a case study of only one program's experience, utilizing a relatively small sample size. Only current students in the program were asked to participate in this study in order to capture data while they were still in the program. Additionally, the survey instrument would have been more definitive utilizing a Likert scale or other previously validated assessment tool.

Validity of the study could also have been supported by the evaluation of specific physical examination competencies rather than the students' overall physical examination competence. For example, evaluation of proper auscultation technique, rather than overall general examination skills, could be evaluated. PANCE scores relative to physical examination could also be analyzed as an outcome but was not completed as part of this study and could be considered for future research. The subjectivity of the student's perception is also recognized as a factor.

A potential follow-up study could include a comparison of students' PANCE performance with regard to format of curriculum delivery (system-based vs. problem-based, and the blended use of both). This comparison may provide additional validity to the use of a particular format.

The hallmark of the physician assistant profession has always included exemplary history taking and physical examination skills. Physician assistant programs can use the results of this study to formulate a style of instruction that fits best with their Program's mission/vision, style and goals. This study demonstrates that these two formats of instruction can be equally effective.

\section{Conclusions}

In conclusion, the results indicate that the majority of students felt that receiving the alternate format would not have provided additional preparedness. Each class felt equally prepared for clinical rotations regardless of the delivery style they received.

Furthermore, student outcomes, as defined by preceptor evaluations of physical examination competency on clinical experiences, were equivalent in both cohorts. This demonstrates that both delivery methods for the physical diagnosis course were equally effective in these groups. These results may be utilized by other PA programs to assist in the development and delivery of the clinical skills courses that are required of each program.

\section{REFERENCES}

1. Wardley CS, Applegate EB, Van Rhee JA. A comparison of student knowledge acquisition by organ system and skills in parallel problem-based and lecture-based curricula. J Physician Assist Educ. 2013;24(1):5-14. [23858821]

2. Maldonado R. The use of multimedia clinical case scenario software in a problem-based learning course: impact on faculty workload and student learning outcomes. J Physician Assist Educ. 2011;22(3):51-5. [PMID: 22070066]

3. Van Rhee JA, Wardley S, Hutchinson C, Applegate EB, Vangsnes E, Meyer J, Grinwis B, Fenn W.e Problem-based Learning in Physician Assistant Education: Establishing a Basis for a Comparative Study. Perspective on Physician Assistant Education. 2004;14(4):242-8.

4. Barrows HS, Tamblyn RM. Problem-Based Learning: An Approach to Medical Education. New York: Springer Publishing Company; 1980:1.

5. Bawazir O. The Holistic Approach to Clinical Problem Solving Using Fishbone Format: A Simple Way for Clinical Reasoning. Education in Medicine Journal. 2014;6(3):72-6.

6. Pelaccia T, Tardif J, Triby E, Charlin B. An analysis of clinical reasoning through a recent and comprehensive approach: the dual-process theory. Med Educ Online. 2011;16:5890. [PMID 31430797]

7. Eva KW. What every teacher needs to know about clinical reasoning. Med Educ. 2004;39(1):98-106. [PMID 15612906]

8. Norman G. Research in clinical reasoning: past history and current trends. Med Educ. 2005;39(4):418-27. [PMID 15813765] 
9. Charlin B, Boshuizen HP, Custers EJ, Feltovich PJ. Scripts and Clinical Reasoning. Med Educ. 2007;41(12):1178-84. [PMID 18045370]

10. Kassirer JP. Teaching Clinical Reasoning: Case-Based and Coached. Academic Medicine. 2010;85(7):1118-24. [PMID 20603909]

11. Jons-Cox $L$. The self-directed osteopathic medical student: Bringing adult learning into the osteopathic manipulative technique lab. International Journal of Osteopathic Medicine. 2014;17:61-5.

12. Murad MH, Coto-Yglesias F, Varkey P, Prokop LJ, Murad AL. The effectiveness of self-directed learning in heath professions education: a systematic review. Med Educ. 2010;44(11):1057-68. [PMID 209466476]

13. Gyawali S, Jauhari A, Shankar $P$, Saha A, Ahamd M. Readiness for self directed learning among first semester students of a medical school in Nepal. J Clin Diagn Res. 2011;5:20-3.

14. Devi V, Devan, D, Soon P, Han W. Comparison of self-directed learning readiness among students experiencing hybrid and traditional curriculum. J Clin Diagn Res. 2012;6:1047-50.

15. Frambach JM, Driessen EW, Chan LC, van der Vleuten CP. Rethinking the Globalization of Problem-Based Learning: How Culture Challenges Self-Directed Learning. Med Education. 2012;46(8):738-47. [PMID 22803751]

16. Wong AK. Culture in medical education: Comparing a Thai and Canadian Residency Programme. Med Educ. 2011;4 (12):1209-19. [PMID 21999309]

17. Leon JS, Winskell K, McFarland A, del Rio C. A Case-Based, Problem-Based Learning Approach to Prepare Master of Public Health Candidates for the Complexities of Global Health. Am Journal of Public Health. 2015;105(S1):S92-6. [PMID 25706029]

18. Farland M, Franks A, Barlow P, Rowe AS, Chisholm-Burns M. Assessment of student learning patterns, performance, and long-term knowledge retention following use of didactic lecture compared to team-based learning. Currents in Pharmacy Teaching and Learning. 2015;7:317-23.

19. Norcini JJ, McKinley DW. Assessment methods in medical education. Teaching and Teacher Education. 2007;23:23950.

20. Smith JS. Active learning strategies in the physician assistant classroom- the critical piece to a successful flipped classroom. J Physician Assist Educ. 2014;25(2):46-9. [PMID 25016916]

21. Gaur L, Skochelak S. STUDENT JAMA. Evaluating Competence in Medical Students. JAMA. 2004;291(17):2143. [PMID 15126448]

22. Milanese S, Grimmer-Somers K, Souvlis T, Innes-Walker K, Chipchase L. Is a blended learning approach effective for learning in allied health clinicians? Physical Therapy Reviews. 2014;19(2):86-93. 


\section{Appendix 1 - Survey Tool}

1. Please check the line that applies to you: Male Female

2. Please check the line that best describes your age:

$21-25$ 26-30 $31-35$ $36-40$ $41-45$ $46-50$ $>50$

3. Why did you choose Chatham University for PA School?

PBL Good Reputation This is where I was accepted Live in Area

Other (Please list)

4. Please check one: Class of 2010 Class of 2011

5. Physical Diagnosis was delivered in the following manner:

System Based

Problem Based

6. I felt well prepared to complete a physical examination that was problem based when I went on my first rotation.

True False

7. I would have felt more prepared to complete a problem focused physical Examination if Physical Diagnosis had been delivered in a case or problem focused style.

True

False

$\mathrm{N} / \mathrm{A}$

8. I would have felt more prepared to complete a problem focused physical examination if Physical Diagnosis had been delivered in a system based style.

True

False

N/A

9. I would have felt more prepared IN GENERAL if Physical Diagnosis had been delivered in a case or problem focused style.

True

False N/A

10. I would have felt more prepared IN GENERAL if Physical Diagnosis had been delivered in a system based style.

True False $\mathrm{N} / \mathrm{A}$

Please offer any additional comments that you wish.

- Note that the original tool was not numbered, but have been numbered here to identify which questions are being referred to in the analysis. 